\title{
Mujeres chinas en España. El capital social y su impacto en las estrategias productivas y reproductivas
}

\author{
Amelia Sáiz López \\ Universitat Autònoma de Barcelona. Departamento de Traducción e Interpretación. \\ Grupo de investigación InterAsia \\ amelia.saiz@uab.cat
}

\section{Resumen}

La mayor parte de la migración china en España es de carácter familiar y procede de la provincia de Zhejiang. Sin embargo, en la última década del siglo pasado, llegaron nuevos flujos migratorios chinos con diferentes motivaciones y capital social. Así, no todas las mujeres chinas disponen de una red familiar en el contexto migratorio. Su ausencia o presencia determina buena parte de sus estrategias productivas y reproductivas. Por otra parte, la conjunción entre familia y trabajo explica si el asentamiento femenino chino se realiza mediante la transnacionalización de actividades de la esfera reproductiva, con la ayuda de la familia extensa residente en territorio español o con la contratación local de servicio doméstico. El análisis del capital social de las mujeres chinas (a nivel transnacional y/o local) ayuda a comprender sus prácticas familiares y empresariales, así como sus relaciones con la sociedad española.

Palabras clave: migración china; familismo; transnacionalismo; localismo; mujeres inmigrantes; maternidad; mujeres trabajadoras.

\section{Abstract. Chinese women in Spain: Social capital and its impact on productive and reproductive strategies}

The major part of the Chinese migration flow to Spain is of a family nature, with most migrants coming from Zhejiang province. In the 1990s, however, new Chinese migration flows with different motivations and social capital arrived in Spain. In this regard, not all Chinese women have a family network in the context of migration and the absence or presence of such a network determines much of their productive and reproductive strategies. In addition, the family/work combination explains whether Chinese women settle in the country through the transnationalization of activities in the reproductive sphere with the help of the extended family residing in Spain, or by hiring local domestic work. The analysis of the transnational and local social capital of Chinese women provides insight into their family and business practices, and their relationship with Spanish society.

Keywords: chinese migration; familism; transnationalism; localism; immigrant women; maternity; women workers. 


\author{
Sumario \\ Flujos y proyectos migratorios Localismo versus transnacionalismo \\ Familia y trabajo. Diferentes Conclusión \\ estrategias de transnacionalización
}

La investigación sobre la presencia china en España ${ }^{1}$ cuenta con más de veinte años de trabajo y producción científica. Uno de los primeros análisis data de comienzos de la década de 1990 (Beltrán, 1991). No obstante, a pesar del tiempo transcurrido desde entonces, todavía son muy pocos los investigadores centrados específicamente en las personas de este origen. En general, la presencia china en España se ha abordado en torno a una o varias comunidades definidas y bien asentadas en el contexto español: la originaria del sur de la provincia de Zhejiang (Beltrán, 1991, 2003; Beltrán y Sáiz, 2001; Nieto, 2001; Moraga, 2010); la procedente de Taiwan (Beltrán, 1991; Nieto, 2001; Betrisey, 2009), y trabajos que aluden al flujo procedente del noreste de China (Beltrán y Sáiz, 2001; Nieto, 2003; Sáiz, 2006; Moraga, 2010).

La problemática de la aproximación comunitaria para estudiar la presencia china en distintos países de Europa dio lugar a un debate académico a comienzos de este siglo. Christiansen (2003) cuestiona el uso habitual de la categoría "comunidad" aplicada a la presencia china en cualquier país, porque implica y connota un "comunitarismo» difícil de constatar en la práctica. La "comunidad» ni es real ni imaginada por sus protagonistas. A nivel identitario, lo que existen son «subetnicidades» marcadas por lugares de origen más concretos, pequeños y localizados. Las presencia china en cada país europeo es heterogénea y cada segmento, grupo o subetnicidad se encuentra lejos de disolverse en una genérica "comunidad china» manifestada por estrechos e intensos vínculos entre sus miembros mediante muestras de solidaridad, ayuda, intercambio de información, etc. En este sentido, la categoría «comunidad», utilizada de un modo acrítico, idealiza y enmascara las divisiones y diferencias. Pieke (2006) se hace eco de esta reflexión y propone que, a nivel identitario, donde únicamente se puede encontrar el «comunitarismo» asociado a "comunidad» es a una escala más micro, en la familia: no hay comunidades chinas, sino familias chinas.

En España, los estudios centrados en algunas de las comunidades o «subetnicidades» chinas presentes han analizado la inserción económica de los migrantes chinos (Beltrán y Sáiz, 2005, 2006) o el papel de las mujeres taiwanesas en la transmisión de la cultura nacionalista comparándolo con el de las originarias de la República Popular (Nieto, 1998), por citar algunos de ellos. Otros enfoques se han centrado en la familia y su papel en la migración (Beltrán, 2000), en la actividad empresarial (Beltrán y Sáiz, 2009; Camarero

1. A fecha 30 de junio de 2011, hay 167.582 residentes de origen chino en España, de los cuales 78.380 son mujeres (46,8\% del total) (Extranjeros residentes en España a 30 de junio de 2011. Observatorio Permanente de la Inmigración, Ministerio de Trabajo e Inmigración). 
y García, 2004), así como en las estrategias familiares de conciliación de las empresas familiares de las mujeres originarias de Qingtian, provincia de Zhejiang (Sáiz López, 2007).

En los trabajos anteriormente citados, se incide en la importancia de las redes familiares y étnicas en el proceso migratorio y de asentamiento chinos. En este sentido, si el capital social hace referencia a las redes y a las relaciones sociales que crean las personas, también sugiere que es un recurso que está relacionado con la pertenencia a estos grupos, sin olvidar que la cantidad de capital social que se tiene depende de la cantidad de conexiones que se pueden movilizar de forma efectiva² (Bourdieu, 1986). Así, a mayor capital social, mayor es la implicación y la presencia de las personas en la red social, lo que muestra la agencia individual y colectiva a la hora de activarla. Por otra parte, para que el capital social sea efectivo, es preciso que exista un grado de confianza entre los participantes y unas normas sociales básicas de reciprocidad (Putnam, 2002), aspectos que estructuran las relaciones coétnicas de cada uno de los flujos migratorios chinos.

Si bien es cierto que el mayor volumen de las residentes chinas en España nacieron en el sur de la provincia de Zhejiang, también lo es que existen flujos consolidados procedentes de las provincias de Heilongjiang, Liaoning, Jilin (noreste de China), Shandong (provincia litoral del norte) y Fujian (provincia litoral y frontera al sur de Zhejiang), además de las ciudades de Beijing, Shanghai, la provincia de Guangdong, Hong Kong y Taiwan ${ }^{3}$. La diversa procedencia de los flujos migratorios chinos a España indica trayectorias diferentes para los hombres y las mujeres que las protagonizan. Ni la motivación ni la disponibilidad de la red familiar y coétnica es igual para ellos ni para ellas. Sin embargo, todas desarrollan estrategias destinadas a compatibilizar el trabajo con las obligaciones y las necesidades familiares en las que el uso del capital social es crucial.

Las esferas productiva y reproductiva no tienen la misma dimensión ni conllevan igual dedicación para todas las mujeres chinas. La presencia o ausencia de la familia nuclear y extensa, el acceso a ella y su disponibilidad, la actividad laboral, la pertenencia a una familia empresaria, ser la pionera e iniciar la cadena migratoria de su propia familia nuclear, ser madre de hijas e hijos pequeños o adolescentes constituyen algunos de los factores que determinan la separación o continuidad del trabajo productivo y reproductivo. Estos factores también inciden en la viabilidad de las estrategias orientadas por lo local o por lo transnacional que afectan a sus recursos, sean económicos o sociales.

2. El término clave en lengua china que remite al capital social es guanxi. El funcionamiento de las redes sociales es tan importante en el mundo chino que se ha desarrollado una disciplina específica para analizarlo denominada guanxixue (literalmente, 'estudios de las relaciones sociales').

3. Aunque, durante aproximadamente treinta años (1953-1983), las personas originarias de Taiwan constituyeron un segmento importante en España del total de la presencia china, con el tiempo han ido disminuyendo frente al constante incremento de las de procedencia continental, de modo que su grupo ha quedado reducido en la actualidad a 415 residentes (Anuario estadistico de inmigración, 2009). 
A partir de un análisis que identifica el origen concreto con proyectos migratorios diferenciados, sean personales o familiares, y las trayectorias de las mujeres y de su trabajo productivo, este artículo propone un modelo explicativo del asentamiento femenino chino articulado en torno a la continuidad o a la separación de la familia y el trabajo. Para ello, se analizan, en primer lugar, las motivaciones de los distintos flujos migratorios y su inserción laboral en el contexto de acogida, sea o no en el interior del nicho étnico chino. En segundo lugar, y teniendo como modelo algunos estudios de caso de trayectorias concretas de mujeres chinas en España, se examina el tipo de estrategias productivas y reproductivas puestas en juego por las trabajadoras, teniendo en cuenta la ausencia o presencia de su familia extensa en el territorio español, como, por ejemplo: transnacionalizar o contratar el trabajo reproductivo. Prácticas que unifican el objetivo de todas las mujeres chinas: mejorar la condición socioeconómica de sus familias, tal y como acredita su participación activa en el sistema productivo empresarial o laboral.

\section{Flujos y proyectos migratorios ${ }^{4}$}

\section{Del sureste de China}

Las mujeres originarias de las provincias de Zhejiang y de Fujian forman parte de un flujo migratorio eminentemente familiar. Sin las redes familiares, gran parte de los llegados a Europa en los últimos treinta años hubieran encontrado más dificultades para poder consolidar su asentamiento y conseguir que fuera exitoso.

Desde las primeras décadas del siglo XX, Europa se erigió como destino de la emigración zhejianesa, con ello se sumó a los, para entonces, ya tradiciona-

4. La información utilizada en este artículo proviene del trabajo de campo realizado en Cataluña a lo largo de una década. Los distintos proyectos de investigación de donde proceden los datos aquí analizados han sido financiados en varias fases y por varias instituciones (Fundació Jaume Bofill, Fundació CIDOB), así como por el Ministerio de Ciencia y Educación en grupos de investigación de la Universidad de A Coruña (ESOMI) y de la Universidad Autónoma de Barcelona (InterAsia). La metodología utilizada siempre ha sido cualitativa, fundamentalmente observación participante y entrevistas en profundidad semiestructuradas que fueron grabadas en varias lenguas, de acuerdo con el uso de las informantes — chino, castellano y catalán - y transcritas en castellano. En función de los objetivos de cada una de las investigaciones, el contenido de las entrevistas realizadas a mujeres adultas variaba; por ejemplo: algunas se centraron más en la conciliación laboral, en la movilidad social ascendente, en la empresa familiar, en la educación de los hijos e hijas, etc., pero en todas ellas, como punto de partida y datos básicos, se ha recopilado una pequeña historia de vida y del proceso migratorio personal, así como de los miembros de la familia extensa, migrantes o no, relaciones con origen y expectativas de futuro. Para este artículo, se ha seleccionado una muestra de 33 entrevistas o casos de mujeres residentes chinas en Cataluña distribuidas por origen: 14 procedentes de Qingtian y 8 de Wenzhou (Zhejiang); 2 de la provincia de Jilin y 2 de Heilongjiang (noreste de China); 2 de la provincia de Shandong; 3 de la de Fujian; 1 de Beijing y otra de Shanghai; por estado civil en el momento de llegada al territorio español: 22 casadas, 8 solteras, 2 divorciadas, y por actividad laboral: 26 propietarias o empleadas en empresas familiares del nicho étnico chino; 3 empleadas en empresas catalanas, 1 en la Administración pública, 2 profesoras de idiomas en escuelas privadas y 1 ama de casa. 
les destinos del sureste asiático y del continente americano que tenían otros orígenes. Los primeros desplazamientos fueron protagonizados por varones, pequeños comerciantes que se dedicaban a la venta ambulante con la intención de regresar a su origen para invertir sus ganancias en tierra o negocios que incrementaran el patrimonio y el prestigio social familiar. Con el paso del tiempo, este flujo migratorio inicialmente masculino y temporal se fue transformando en familiar, permanente y circular ${ }^{5}$. Qingtian y Wenzhou conforman lo que se conoce como qiaoxiang, término que alude a una zona, a un distrito o a una comarca especializada en la migración internacional. Los qiaoxiang son comunidades cuya fuente de ingresos es la emigración de las personas en edad laboral. Las más investigadas en los estudios de migración china corresponden a las ubicadas en la provincia de Guangdong (Douw et al., 1999; Hoe, 2004). Qingtian y Wenzhou también han llamado la atención de investigadores europeos (Beltrán, 2003; Pieke y Malle, 1999; Hoe, 2004), como también la provincia de Fujian (Pieke et al., 2004), donde el distrito de Changle es el origen de las cadenas migratorias familiares más recientes en España.

El fin de la Revolución Cultural (1976) dio paso al comienzo de la era posmaoísta en China, caracterizada por las reformas y los cambios sociales y la apertura económica que ha facilitado el desplazamiento humano entre Europa y China. En efecto, desde finales de la década de 1970, entran en escena con un nuevo ímpetu las cadenas familiares y étnicas de migración hacia diferentes destinos, y el continente europeo es uno de ellos. Paralelamente al incremento del flujo migratorio chino, se configura la vía de movilidad social ascendente preferente en Qingtian y Wenzhou: obtener el éxito económico en Europa $(\mathrm{Li}$, 1999; Beltrán, 2003). El itinerario para conseguirlo se perfila y se circunscribe dentro del nicho étnico chino de los países europeos a partir de los negocios familiares (Reis, 2010).

El nicho étnico ofrece varias ventajas. En primer lugar, acoge a los recién llegados facilitándoles trabajo y alojamiento en sociedades de las cuales, generalmente, desconocen las lenguas y el modo de funcionamiento. En segundo lugar, sirve para capacitar a los emprendedores y las emprendedoras chinos. Debido a la poca cualificación profesional de la primera generación de migrantes, la práctica mientras se trabaja para otros, sean o no miembros de la familia extensa, constituye el medio clave para adquirir las habilidades y las técnicas necesarias para que sus futuros negocios tengan éxito. Así, por ejemplo, mediante la experiencia directa adquirida por el trabajo asalariado en el nicho étnico, se aprende a gestionar empresas en aspectos relacionados con su funcionamiento (contratación, proveedores, contactos, etc.) y con el ámbito

5. Tarrius habla de las migraciones nómadas y circulares que rompen con la clásica oposición entre ser de aquí o de allí. Llama la atención sobre la capacidad de ser de los dos espacios simbólicos a la vez: «El adolescente con edad de integrarse en el mercado laboral se desplaza a lo largo de las redes para reunirse con un conocido o con un familiar en un país de Europa, o incluso más lejos» (Tarrius, 2004: 309). El caso chino se ajusta más a una perspectiva de análisis transnacional, pero aquí interesa señalar el cambio de modelo migratorio que ha experimentado el flujo procedente de Zhejiang desde sus inicios hasta ahora. 
legal (leyes, regulaciones, impuestos, etc.) específicos de la sociedad de destino donde se establecen, ya que cada país tiene sus propias leyes empresariales y comerciales. La independencia empresarial se alcanza cuando la acumulación de capital — que incluye el acceso y la disponibilidad de dinero proporcionado por miembros de la familia extensa y de la red étnica - es suficiente para establecer una empresa familiar de carácter básicamente nuclear. En definitiva, facilita a los empleadores el reclutamiento de mano de obra barata, que habitualmente está compuesta por parientes y paisanos contratados en origen, así como también proporciona la formación que posibilita la futura trayectoria empresarial de los empleados.

En tercer lugar, el nicho étnico propone un modelo de éxito económico basado en la empresa familiar que ofrece continuidad, porque, por un lado, la red familiar y coétnica financia el posible fracaso de las iniciativas empresariales fallidas (Beltrán y Sáiz, 2009) y, por otro, incorpora a los hijos e hijas como recursos humanos de la empresa con una división generacional del trabajo muy clara: los padres inician la cadena migratoria y la acumulación de capital inicial, y los vástagos en edad escolar se encargan de aprender las lenguas locales, así como los valores de la sociedad de destino en la escuela (Sáiz López, 2006). Del mismo modo, los hijos e hijas que realizan estudios universitarios suelen complementar la herencia familiar mediante la creación de nuevas empresas, donde se ponen en práctica los conocimientos teóricos adquiridos con los estudios superiores (Sáiz López, 2010).

Este sistema chino de inserción económica en Europa y España se basa, como hemos visto, en la empresa familiar. Así, hombres y mujeres, jóvenes, niños y niñas han emigrado casi siempre de manera escalonada: primero, el hombre adulto; luego, la mujer con o sin los hijos o hijas; o, por el contrario, es la esposa la que inicia la migración seguida del marido y de los hijos o hijas, todo depende de cual de los dos cónyuges sea el que cuenta con los familiares en Europa necesarios para proporcionar la ayuda durante la primera fase de la migración. Si es la mujer, ella se convierte en la llave para la migración de la familia del marido, circunstancia que modula el efecto del sesgo patriarcal y patrilineal de la familia rural china, con lo cual se equilibran hasta cierto punto las relaciones de género en el interior de la familia nuclear y extensa.

La combinación del modelo económico de movilidad social ascendente con la cultura familista ${ }^{6}$ del mundo rural chino explica que tanto hombres

6. En la producción científica española relacionada con la migración (GESES, 2008; Solé y Lurbe, 2006) y el estado de bienestar (Añón y Miravet, 2005), se está usando el término familiarista para señalar la adjudicación del trabajo reproductivo y de cuidados a la familia $y$, en especial, a las mujeres de las familias, sean esposas o hijas. En la medida en que las relaciones familiares y laborales en el seno de la familia china no están definidas por el estado de bienestar de los países de acogida, utilizamos el término familismo desde una perspectiva antropológica clásica, definido como «[...] un sistema social donde la conducta, las normas, los ideales, las actitudes y los valores surgen del bienestar, se centran en el bienestar o van dirigidos hacia el bienestar de aquellos que están vinculados por el nexo de sangre (Kulp, 1925: 29; Lin, 1947; Lau, 1978), que se adecua más a la perspectiva emic de la cultura china, cuyo punto de vista es el que se analiza en este artículo. 
como mujeres participen en la consecución del éxito y, por extensión, de la migración. Ambos pueden ser igualmente protagonistas y agentes motores en la medida en que dispongan de los medios y las condiciones para iniciar el proyecto migratorio. El familismo también explica la implicación de las mujeres en todo el ciclo de la empresa familiar, desde la acumulación de capital hasta su expansión, pasando por la fase de consolidación (Sáiz López, 2007). En cada una de las fases del ciclo de la empresa, la aportación de la esposa es tan necesaria e imprescindible como la del marido, en ocasiones incluso más. Y el nicho étnico también las promociona (Ceccagno, 2007). Sin embargo, el trabajo y el valor de las mujeres no suponen un cuestionamiento de las relaciones de género familiares, en las que tradicionalmente ellas han ocupado una posición subalterna en relación con los varones adultos y con el esposo, sino que se interpreta en clave familiar. Y aunque las mujeres valoran positivamente poseer negocios — estén o no a su nombre- ${ }^{7}$, porque ello incrementa su valor económico en la familia, la lógica familista proporciona el marco ideal para que la presencia femenina en la esfera productiva no altere el sistema de género, ya que es una obligación de los padres proporcionar a sus hijos e hijas las mejores condiciones de vida posibles.

\section{Del noreste de China}

El flujo migratorio procedente de las provincias de Heilongjiang, Jilin, Liaoning (dongbei, noreste de China) y de la de Shandong aparece en Europa a finales de la década de 1990. Las reformas económicas acometidas por China desde la década de 1980 desembocaron en una reconversión importante de las empresas estatales, muchas de ellas traspasadas a manos privadas o mantenidas en régimen semiprivado y otras cerradas. Este proceso se aceleró en 1997-1998 en el ámbito urbano, con un incremento de aproximadamente 20 millones de parados. En cualquiera de los casos, la situación de los trabajadores y las trabajadoras empeoró. Para ahorrar costes, las empresas estatales empezaron a despedir preferentemente a las mujeres. Las empresas privadas ofrecían sueldos más bajos y menos prestaciones sociales (Sáiz López, 2001). A mediados de la década de 1990, el despido laboral en el mundo urbano llegó también a los hombres. Una alternativa que se les presentó a ellos y ellas fue la migración hacia Europa.

Su relativa reciente aparición indica la inexistencia de un asentamiento consolidado de estos orígenes en el continente europeo, es decir, no tienen un nicho económico propio, razón por la que buena parte de las personas procedentes de este nuevo flujo migratorio se insertaron en el ya existente y trabajaron como asalariadas para las personas chinas de Zhejiang ya asentadas en Europa.

7. «Bueno, es cierto que he tenido que trabajar mucho hasta llegar aquí. Sí, ha sido duro, pero sabes, para las mujeres, es muy bueno tener una tienda o algo así, nos da tranquilidad y confianza en el futuro» (empresaria de Qingtian). 
La ausencia de un nicho étnico propio de los originarios de dongbei ${ }^{8}$ apunta a una pauta migratoria distinta de la anteriormente comentada. La carencia de un asentamiento histórico reduce las posibilidades de una comunidad de familias extensas con proyectos colectivos de desarrollo económico. Para la mayoría de las personas procedentes de estas provincias, que son de origen urbano y con antecedentes laborales de asalariados en fábricas estatales, el proyecto migratorio es individual o, como mucho, implica a la familia nuclear, habitualmente de hijo o hija único. Hombres y mujeres deciden emprender el viaje "para probar suerte» y comprobar in situ la realidad de los comentarios y rumores que circulaban por sus ciudades sobre la amplia oferta laboral, acompañada de buenos sueldos de «la rica Europa».

El hecho de no disponer de una red familiar o de coétnicos en el país de destino no es un impedimento para conseguir trabajo. En los diversos nichos étnicos chinos, siempre hay necesidad de mano de obra para satisfacer la demanda estacional de los mayoristas, para servir las mesas de los restaurantes, en las cuadrillas de albañiles para la construcción, etc. En general, trabajos no cualificados y temporales del mercado laboral chino. La movilidad acompaña a la vida dentro y fuera del nicho étnico, a los asalariados y a los empresarios. Los primeros, en busca de la mejor oferta laboral; los segundos, en busca de la mejor oferta comercial. La movilidad también es geográfica dentro del continente, ya que el nicho étnico recorre los países de Italia, Francia, España y Portugal, principalmente. La decisión de permanecer en uno de ellos viene determinada, entre otras cosas, por la situación jurídica: allí donde consiguen regularizarse, por lo general, fijan su residencia.

La movilidad laboral es posible por el acceso a la oferta ocupacional. A falta de una red propia, los tablones de anuncios de los supermercados de productos chinos y de otras tiendas y servicios ubicados en las zonas de residencia coétnica, junto con los periódicos editados por las distintas comunidades chinas en Europa, son los medios habituales en los que pueden informarse sobre las distintas ofertas laborales. Las mujeres acostumbran a trabajar en la confección, en la restauración, en el comercio y en el servicio doméstico para las familias chinas del sureste 9 y utilizan las mismas vías para obtener trabajo que sus compatriotas varones ${ }^{10}$. En el nicho étnico chino, más que discriminación laboral de género, existe —en algunas ocupaciones - la división sexual del trabajo.

8. La producción bibliográfica europea sobre este flujo migratorio es escasa. En Francia, algunas académicas han estudiado las razones por las que emigran las mujeres procedentes del noreste de China (Levy, 2005a), sus condiciones laborales (Levy, 2005b; Pina-Guerassimoff, 2006) y su relación con la prostitución (Levy y Lieber, 2008).

9. «[...] en casa tengo la ayuda de una mujer de Shandong. Ella limpia y cuida de mi hijo pequeño [ 4 años]. Vive en casa, con nosotros. Ahora hay muchas mujeres de dongbei en España y no están tan organizados como nosotros, los de Qingtian...» (empresaria de Qingtian).

10. Una de las informantes procedente de Heilongjiang estuvo los dos primeros años de su estancia en España viajando por el país de restaurante en restaurante chino. A través del periódico, se informaba de las ofertas laborales. Siempre encontró trabajo sin dificultad entre los compatriotas chinos hasta que decidió introducirse en el mercado laboral de empleadores españoles. 
Con la llegada de las personas de dongbei, el mercado laboral español ha ampliado su diversidad étnica, pues por primera vez los trabajadores de origen chino han pasado a trabajar directamente para empleadores españoles, a excepción de las cuadrillas de albañiles de la construcción, cuyo jefe mediato era también chino. Desde mediados de los años noventa, el mercado laboral español ha cubierto muchos puestos no cualificados y semicualificados en la industria, la agricultura, el campo, la construcción y los servicios con mano de obra de origen extracomunitario. Hombres y mujeres del noreste chino aparecen en ciudades grandes, medianas y pequeñas de la geografía española, en especial en la madrileña y la catalana, para trabajar en fábricas de embalajes, de maquinaría, de transformación agraria, cárnicas, etc. ${ }^{11}$. El reclutamiento de la mano de obra se lleva a cabo por agencias de contratación laboral en el territorio nacional y por conocidos, y las prestaciones de las trabajadoras y los trabajadores chinos son reconocidas por sus empleadores. Valoran la disciplina, la productividad y su disponibilidad permanente ${ }^{12}$. Para las trabajadoras y los trabajadores chinos del noreste, el mundo de la empresa (no familiar) no es ajeno. Muchos de ellos han pasado buena parte de su vida trabajando en una, aunque fuera a varios miles de kilómetros y bajo otro régimen económico.

Según las informaciones facilitadas por las informantes originarias del noreste chino, la diferencia sustancial en trabajar para empleadores españoles o chinos no radica en el aspecto económico, pues si bien el sueldo en el mercado laboral chino es, por lo general, menor que en el mercado nacional, se compensa por las condiciones laborales, ya que, y de acuerdo con la organización laboral china, el empleador facilita la vivienda a sus empleados. Al trabajar en empresas autóctonas, se puede estar en contacto o no con los compatriotas, opción menos factible en el nicho étnico. Disponer de una vivienda personal o compartida con otras mujeres fuera de las redes sociales chinas, aunque las compañeras de piso sean compatriotas, es la pauta residencial que desean y buscan las mujeres de la muestra que han dejado a sus hijos en edad escolar a cargo del padre después del divorcio y esperan reunirse con ellos para realizar estudios superiores en España.

\section{Del resto de China}

Desde la década de 1980, las grandes ciudades de China, como Beijing, Shanghai, Guangzhou y su zona metropolitana, han acogido a una parte importante de los aproximadamente 200 millones de personas que integran la "población flotante» (liudong renkou) del país, el flujo migratorio del campo a la ciudad. La abundancia de mano de obra disponible incrementó la com-

11. El caso más paradigmático lo encontramos en Olot, provincia de Girona, ciudad de 34.000 habitantes con 1.046 residentes chinos en la actualidad, que pasó de 16 empadronados chinos en 2002 a 928 en 2008 (Instituto de Estadística de Cataluña: http://www.idescat. cat/es/mapa.html\#poblacio).

12. Comunicación personal de empleadores catalanes. 
petencia, y ello sumado a las dificultades de las empresas estatales, tuvo como consecuencia la dificultad para conseguir buenos sueldos, motivo que, según las informantes, alentó la emigración.

Comparten con el grupo anterior un proyecto migratorio personal o de familia nuclear. Hombres y mujeres casados, solteros y divorciados deciden salir de su país para desarrollar una actividad profesional o llevar a cabo un cambio en su vida personal. Generalmente, no cuentan con una red familiar o coétnica previa para facilitar su salida e inserción en destino, pero disponen de una formación profesional que les permite acceder a trabajos y a profesiones cualificadas $^{13}$. En este colectivo habría que incluir también a los integrantes de la denominada "emigración de trabajadores de elevada cualificación", un flujo migratorio que poco a poco incrementa su volumen en España, aunque continúa siendo muy minoritario en el conjunto de los residentes y las residentes chinos. Cuando no tienen formación o no es suficiente para acceder a ocupaciones cualificadas, siempre está el recurso de encontrar trabajo en el nicho laboral étnico chino.

La inserción laboral de las personas chinas se mueve entre el trabajo para empleadores chinos, españoles o una combinación de ambos. Una de las variables que explican uno u otro circuito laboral es la presencia de la red familiar en España.

\section{Familia y trabajo. Diferentes estrategias de transnacionalización}

Meili14, nacida en Qingtian en 1976, llegó a España en 1996 y hasta el año 2002 no montó su propio negocio. Es la pequeña de seis hermanos, un hermano y cinco hermanas, tres de las cuales viven también en España. Llegó a Cataluña para trabajar de camarera en el restaurante de su primo. Dos años después (1998), cambia de actividad para trabajar en el taller de un paisano. Se casa en 1999 y en 2001 nace su hijo, la hija llega en 2003, y ambos pasan su primera infancia en Qingtian, el hijo al cuidado de la suegra, la hija con la hermana que no emigró. Cuando cumple cinco años, el niño se escolariza en Cataluña; la niña lo hará con siete. De las tres hermanas que también están en Cataluña, una tuvo un pequeño taller de confección con su marido y las otras dos, ambas casadas, vivieron con ella varios años mientras el resto de sus familias nucleares respectivas se quedaba en origen. Mientras vivían en su casa, se dedicaban a coser ropa para mayoristas chinos y nacionales. El marido de Meili, además de proveer de fruta y verdura la tienda que tuvieron hasta 2005, también se encargó de buscar trabajo a las cuñadas. Desde que se trasladaron a una ciudad en el interior de Cataluña para abrir un bazar, sus hermanas ya no les acompañaron. Una continuó trabajando cosiendo en el taller de su otra hermana y la otra regresó al país de origen.

13. Algunas mujeres del noreste chino también tienen este perfil profesional.

14. Para preservar el anonimato de las informantes, los nombres que las identifican en este artículo son ficticios. 
La trayectoria de Meili es bastante representativa del modelo migratorio qingtianés. En primera instancia, la familia extensa y el nicho étnico acogen a los futuros emprendedores. Se trata de una ayuda con un peso variable en los proyectos empresariales de la familia nuclear a lo largo del tiempo, lo que constituye un rasgo peculiar en la estructura organizativa de las familias transnacionales. Por ejemplo, en lo que respecta a la esfera productiva, a la acumulación de capital de Meili y de su marido para el primer negocio, hay que sumar la contribución de las hermanas. La hermana - que también cuida a los hijos de la hermana propietaria del taller de confección-y la suegra en origen se encargan de la esfera reproductiva.

Con independencia del continente de procedencia, la mayor parte de las familias transnacionales asentadas en España lo son en primera instancia por razones productivas. Hombres y mujeres migran dejando atrás a sus esposos, esposas, hijos e hijas a fin de obtener los ingresos necesarios para ofrecerles mejores condiciones de vida en origen. Ahora bien, en las familias transnacionales, hay por lo menos tres componentes a tener en cuenta para comprender su estructura:

1. El lugar (origen o destino) en el que se desarrolla.

2. La actividad (productiva o reproductiva).

3. Los miembros del grupo doméstico (familia nuclear o familia extensa) que la forman.

En relación con los flujos femeninos, el caso de las mujeres filipinas y primeras emigrantes ecuatorianas fueron paradigmáticos de esta reestructuración familiar que genera un espacio social transnacional, en el que se desarrollan nuevas dinámicas familiares transnacionales y su relación con los cambios en las pautas de crianza (Parreñas, 2003; Pedone, 2007; Parella, 2007). El modelo general de estrategia familiar del proyecto migratorio de las familias transnacionales establece una división femenina del trabajo: el productivo, realizado por las mujeres que migran en destino, y el reproductivo, encargado a las mujeres que permanecen en origen. Muchas de las primeras se dedican a labores domésticas y de cuidados para familias españolas, trabajo reproductivo para terceros fuera de la red familiar extensa. Los hijos e hijas que quedaron en origen se reunifican con el paso de los años con sus madres, así como los maridos. La reunificación escalonada familiar es tan común a la migración como lo son las remesas, imprescindibles para el trabajo reproductivo de las familias transnacionales.

En este esquema, la familia extensa es la encargada de la esfera reproductiva y habitualmente se ocupan de ella los miembros de la misma que permanecen en origen. Sólo cuando se produce un cambio de actividad laboral en destino se reestructura la combinación transnacional, que pasa del trabajo productivo en destino llevado a cabo por los miembros de la familia extensa, al trabajo reproductivo en destino, del cual también se encargarán los miembros de la familia extensa, que lo combinan con el reproductivo en origen. Esta posibilidad no se aplica al grupo de mujeres filipinas en España, que forma parte del conjunto 
de los flujos migratorios más feminizados, dada su casi total inserción laboral en el servicio doméstico y su poca presencia en otras actividades productivas, sean asalariadas o autónomas (Salazar, 2001; Ribas-Mateos y Oso, 2005). En este sentido, resulta pertinente recordar que el cambio de régimen salarial, de asalariada a empresaria, va acompañado de un cambio en la organización familiar (Beltrán, Oso y Ribas, 2006)

El caso de las familias transnacionales pertenecientes a los flujos migratorios más masculinizados en España — como, por ejemplo, el pakistaní- suele dejar en origen a la familia nuclear y extensa, de manera que la división familiar del trabajo es equivalente a la migración femenina: trabajo reproductivo en origen y productivo en destino, con la salvedad que en origen son las esposas y las madres de los migrantes las que llevan a cabo el cuidado de las personas (Beltrán y Sáiz, 2008). La mayoría de los hombres migrantes en España se insertan como asalariados para empleadores españoles y no españoles residentes en el territorio español (Pajares, 2010) y, como en algunos de los casos anteriores, con el tiempo la familia nuclear se reunifica en destino. A este simplificado esquema general, podemos añadir alguna variante.

En todo el flujo migratorio procedente del continente asiático, el colectivo pakistaní es el opuesto al filipino, es decir, es el más masculinizado. La distancia en la presencia de hombres y mujeres en destino se reduce con el paso del tiempo, pero, aún así, todavía hay más hombres que mujeres en el territorio español. Las esposas y las madres están en origen al cuidado de la descendencia y la reunificación es también escalonada y muy lenta. En ocasiones, prima la llegada de los hijos varones adolescentes antes que la de la esposa, división transnacional del trabajo común a la migración masculina. Pero en el flujo pakistaní, hay que añadir, al trabajo productivo realizado en destino, la aportación de la familia extensa en la puesta en marcha y la consolidación de las empresas familiares que instauran en España (Beltrán y Sáiz, 2009). En el caso pakistaní, la familia extensa y la nuclear están presentes, tanto en ambas esferas (productiva o reproductiva), como en los dos polos que configuran su transnacionalismo.

Por su parte, en el caso chino, y según sea la procedencia del flujo migratorio concreto, se da una gradación en las relaciones familiares transnacionales, sean de familia extensa (provincia de Zhejiang y Fujian) o nuclear (noreste y resto del país).

La empresa familiar china en España se caracteriza por la yuxtaposición del ciclo familiar y el empresarial. Habida cuenta de la disponibilidad transnacional, las familias quingtianesas desarrollan su proyecto empresarial en fases que toman en consideración tanto el aspecto productivo como el reproductivo. $\mathrm{Si}$, en la fase de acumulación, han emigrado uno o los dos cónyuges, cuando tienen hijos permanecen al cuidado de la familia extensa hasta que la familia nuclear se reunifica en destino. Partiendo de la base de que la reunificación es legalmente posible, la causa más habitual para llevarla a cabo es la eventualidad de los padres de combinar su cuidado con el de la empresa, es decir, los hijos e hijas son adolescentes, están escolarizados en el sistema educativo español y el 
negocio está consolidado. El tiempo en que el ciclo familiar y empresarial llega a este punto puede variar según la trayectoria empresarial específica de cada familia, pero la pauta general es la reunificación de todos los miembros de la familia nuclear, dada la importancia productiva que tiene la maximización de los recursos humanos disponibles para este tipo de empresas.

Los miembros de la familia extensa también participan, en diverso grado, tanto en el proceso de acumulación, como en el del establecimiento del negocio o en la fase de consolidación. El tejido comercial de las personas originarias del sur de la provincia de Zhejiang está compuesto por redes familiares y coétnicas, familias extensas que operan en destino para que sus empresas sean competitivas y sea posible mantener activo el nicho económico étnico. Se puede afirmar, por tanto, que las familias empresarias de reunificación familiar escalonada en destino se organizan en torno a una división transnacional del trabajo - productivo en destino y/o reproductivo en origen-, y la transnacionalización de la familia extensa que se dedica al trabajo reproductivo en origen mientras que desarrolla el trabajo productivo en destino.

Según los datos estadísticos, el 14\% de las personas chinas residentes ha nacido en España ${ }^{15}$. Una cohorte que va en aumento con el paso del tiempo y que diversifica el origen y los procesos de socialización de la juventud de origen chino en España. El número de niños y niñas también se incrementa: el 23\% del total de la población china que vive en España tiene menos de 15 años $^{16}$. La mayoría son hijos e hijas de matrimonios jóvenes en edad laboral, es decir, con empresas familiares incipientes. En esta fase del negocio, la conciliación de la vida familiar y productiva es de vital importancia para su supervivencia, teniendo en cuenta que una - la familia - y otra - la empresa - crecen paralelamente. El modelo de conciliación elegido depende de la disponibilidad de la familia extensa en cada caso concreto.

Li Hua llegó a España en 2004, donde sus padres son propietarios de un taller de confección. En 2006 se casó, tuvo a su primer hijo y abrió su primer negocio (venta de telefonía móvil). Anteriormente formaba parte de la empresa familiar, pero, al casarse, se independizó, y a una nueva unidad familiar le correspondió una nueva empresa. La dedicación del matrimonio a su empresa es a jornada completa. Ella, que habla mejor las lenguas locales, atiende a los clientes y a los proveedores; él se encarga de la atención técnica y prepara su próxima inversión, una empresa de importación y exportación. Su segundo hijo nació en 2009. Tanto el primero como el segundo han estado al cuidado de una pariente que vive con ellos y a quien pagan una módica cantidad por su trabajo.

Meili llevó a origen a sus hijos nacidos en España para poder dedicarse por completo al trabajo productivo. La transnacionalización del trabajo reproductivo, tan común en los flujos migratorios feminizados y en las empresas familiares transnacionales, en esta ocasión presenta una modalidad exclusiva y

15. Anuario estadístico de inmigración, 2009. Ministerio de Trabajo e Inmigración.

16. Ibídem. 
propia de la migración china: el flujo migratorio de los bebés que son enviados al lugar de origen de los padres. Esta «migración infantil» es de carácter temporal. Ante la imposibilidad de liberar mano de obra en la familia extensa para cuidar de los niños y las niñas nacidos en la nueva unidad familiar, suelen pasar su infancia al cuidado de sus abuelas y/u otros miembros de la familia extensa en Qingtian, hasta que retornan al país de destino cuando alcanzan la edad de iniciar su escolarización.

Li Hua opta por otra estrategia de conciliación laboral. En lugar de transnacionalizar el trabajo reproductivo, sigue la pauta de las madres trabajadoras nacionales contratando el servicio doméstico de una migrante que, además, es del mismo origen y pariente. $\mathrm{Al}$ igual que en el caso anterior, miembros de la familia extensa realizan el trabajo reproductivo, pero en esta ocasión se lleva a cabo en destino, pues la familia natal de Li Hua está aún en edad laboral productiva en destino, es decir, ni su madre ni su suegra están en disposición de cuidar a sus hijos en origen ${ }^{17}$.

No obstante la diferente estrategia reproductiva, tanto Meili como Li Hua son mujeres que, para poder trabajar en la empresa familiar, potencian su dimensión productiva sobre la reproductiva. Se trata de empresarias a tiempo completo alternado con una maternidad presencial temporal, en el caso de $\mathrm{Li}$ Hua, y otra que se desarrolla en un espacio transnacional afectivo, como la que ejerce Meili.

En los estudios de migración y género sobre la maternidad transnacional, el flujo asiático que ha generado una mayor producción bibliográfica es el filipino. Las mujeres filipinas no delegan sus obligaciones maternales a otros miembros de su red de parentesco al emigrar y construyen lo que Parreñas denomina "maternidad intensiva». Las madres filipinas se sienten responsables de la seguridad emocional de sus hijos después de migrar y lo demuestran mediante el envío mensual de remesas a sus familias y manteniendo cuentas bancarias conjuntas con las hijas mayores, aún en el caso de que el padre esté viviendo con la descendencia, y con ello acceden inmediatamente a cubrir las necesidades materiales de sus familias en origen. Además, mantienen conversaciones telefónicas con una periodicidad semanal para estar informadas, entre otras cosas, de los estudios de los hijos, y a las hijas también les consultan sobre el bienestar del conjunto de la familia (Parreñas, 2005).

Meili también enviaba remesas a su familia extensa, hablaba con sus hijos por teléfono y recibía los vídeos que la familia filmaba para que ella fuera testigo de cómo crecían y lo bien cuidados que estaban. Ella les mandaba productos que allí no se encontraban con facilidad o que eran de calidad peor - productos de alimentación infantil, higiene personal y ropa para los críos, sobre todo. En el caso concreto de las madres quingtianesas asentadas en Eslovenia, la leche en polvo se ha convertido en el producto estrella que representa

17. La norma adjudica a la familia paterna el cuidado de la prole de los hijos migrantes debido al sesgo patrilineal de la familia rural china, sin embargo, y el caso de Meili así lo sugiere, hay diversas pautas en función de las estrategias productivas de la familia nuclear migrante. 
al cuidado maternal diario (Bofulin, 2010). En el caso español, este producto es un elemento más de los envíos más o menos regulares a origen, pero no se asume como elemento clave. Por el contrario, la práctica de la maternidad transnacional china remite a un conjunto de acciones realizadas en origen por la madre y en destino por las abuelas, las hermanas o las cuñadas encargadas del trabajo reproductivo, para que las niñas y los niños mantengan una relación afectivo-simbólica con sus padres.

Por otra parte, no es inusual que, a la transnacioanalización del trabajo reproductivo de la empresa familiar, las madres le adjudiquen motivos culturales. En el trabajo de campo, se han registrado frases del tipo «[mis hijos] están en Qingtian porque quiero que conozcan la lengua y la cultura de mi país», aunque, cuando se refieren a niños y niñas menores de cinco años, incluso en el caso de que ya vayan a la escuela en China, su asistencia todavía no tenga una finalidad educativa. La verdadera instrucción se realiza en España. Para facilitar el aprendizaje de la lengua oficial china ${ }^{18}$ a los hijos e hijas escolarizados en territorio español, los padres han organizado asociaciones culturales para gestionar escuelas que funcionan en horario extraescolar, especialmente durante los fines de semana. En estas escuelas, además de lengua, se enseña cultura china (Beltrán y Sáiz, 2001; Nieto, 1998). El aprendizaje de la lengua y la cultura chinas desde mediados de la primera década del siglo XXI se complementa con la asistencia a las escuelas de verano organizadas en Qingtian. Las visitas y las estancias familiares y educativas permiten a los hijos e hijas de las familias chinas de la diáspora establecer vínculos afectivos con la tierra originaria de los padres e incorporar los valores de la ideología familiar rural, con lo que se refuerzan los lazos de la familia transnacional.

Las madres empresarias qingtianesas saben que su maternidad transnacional no es normativa en el contexto de la sociedad española. La residencia cercana de los abuelos y las abuelas, por un lado, y la cadena global de cuidados, por otro, facilitan cuidadoras a las madres trabajadoras nacionales, con lo cual evitan el traslado de sus hijos e hijas en edad infantil a otras poblaciones. Dejando de lado los sentimientos de las madres empresarias chinas, concentrarse en el ámbito productivo de sus familias empresarias — esforzarse en el trabajo- es, por extensión, una manera de realizar trabajo reproductivo, pues familia y empresa componen un todo inseparable, a pesar de la movilidad y de la transnacionalización. Familia y trabajo son dos caras de la misma moneda, dos ámbitos de sus vidas, ambos igual de importantes, porque, en su experiencia de empresarias qingtianesas, sin la familia es más difícil que el trabajo sea fructífero y exitoso.

En ausencia de una cultura familiar emprendedora como la de Qingtian, las madres trabajadoras originarias del noreste de China concentran sus energías para que sus hijos e hijas accedan a una buena educación superior, en China o en España. En este sentido, comparten con sus congéneres meridionales su 
sentido de la obligación maternal: el trabajo está destinado a conseguir el mejor futuro posible para su descendencia. Y también comparten con ellas la maximización de los recursos disponibles. Para las madres divorciadas del noreste chino, una de sus aspiraciones es que sus hijos e hijas accedan a la educación superior, sea en China o en España. De hecho, España se convierte en una alternativa y en una posibilidad para lograr este fin a pesar de que el idioma sea una dificultad añadida, especialmente si se tiene en cuenta que las pruebas de selectividad para el acceso a la universidad son muy exigentes y competitivas en China, debido a la escasez de plazas universitarias.

Este sentido de la maternidad también es compartido por las mujeres que permanecen en origen. En el trabajo de campo, se han descubierto casos en los que, tras una ruptura matrimonial, el padre emigra y el hijo o la hija queda en primera instancia al cuidado de la madre en origen (noreste chino) hasta llegar a la edad de cursar los estudios superiores. Un poco antes de cumplir los dieciocho años, de acuerdo con los requisitos legales de la reunificación familiar, se reúnen con el padre en España. Una práctica que está en consonancia con la tendencia, relativamente reciente, entre familias de origen asiático de transnacionalizar una parte del grupo doméstico nuclear para elevar el estatus familiar, con lo cual incrementan el capital cultural y simbólico más que el económico. Por ejemplo, las madres de las familias más adineradas de Hong Kong, de China o de Corea del Sur se trasladan con sus hijos en edad escolar a países como Singapur, Canadá, Estados Unidos o Reino Unido para escolarizarlos y asegurarles una mejor educación. Se trata de una estrategia familiar y no exclusivamente individual, para adquirir un capital simbólico internacional. Con ello capacitan a sus hijos e hijas en el desarrollo de competencias cosmopolitas que gozan de un gran valor en el mercado laboral local e internacional de los ámbitos profesionales, financieros y empresariales (Yeoh, Huang y Lam, 2005).

En definitiva, el recurso de diversos ámbitos transnacionales adquiere diferentes tipologías y funciones según la estructura familiar, las necesidades de sus integrantes y las expectativas que los padres y las madres tienen sobre el alcance de su proyecto migratorio, representado por el futuro de su descendencia.

\section{Localismo versus transnacionalismo}

La diversidad de orígenes geográficos está asociada con diferentes modelos de inserción laboral en la sociedad de destino. La dialéctica entre norte y sur de origen no sólo pone a prueba las generalizaciones sobre el colectivo, sino que también obliga a precisar pautas y dinámicas desde una perspectiva multivariable. La conjunción entre familia y trabajo perfila unas estrategias de asentamiento basadas en el uso diferenciado del espacio y de la familia transnacional. La lógica familista propia de la cultura rural china se adapta a las necesidades del capitalismo (global) tardío, movilizando los recursos humanos y financieros de la familia en un orden inserto en prácticas transnacionales, al superponer a la frontera jurídica del territorio una serie de estrategias económicas y familiares 
que encuentran en la circulación o movilidad — de capitales, de información, de formación, de recursos humanos, entre otros - su mejor baza para su supervivencia, continuidad y éxito.

Sin embargo, y como ya se ha señalado, la diversidad del flujo chino en España da lugar a vías alternativas de asentamiento. Las personas residentes procedentes del noreste de China y de sus grandes urbes carecen del recurso de la familia transnacional. En algunos casos, la obtienen a partir de su matrimonio con hombres y mujeres de Qingtian y Wenzhou asentados ya en el Estado español o en otros países europeos. El futuro del nuevo matrimonio, como el del resto de sus compatriotas meridionales, es la empresa familiar. Pero hay otras posibilidades.

Yang Mei llegó a España en 2003, con veintiséis años, procedente de la provincia de Shandong. En su país se licenció en literatura china, una formación poco competitiva en el mercado cualificado en origen. Buscando trabajo, coincidió con una antigua compañera que le comentó la posibilidad de emigrar a Europa: una amiga suya que llevaba varios años en España era testigo del creciente interés de los españoles por el estudio de la lengua china. Yang Mei llegó para trabajar en la academia de idiomas de la amiga de su compañera ubicada en la ciudad de Barcelona. Mientras enseñaba chino a los estudiantes españoles, ella aprendía lengua castellana con estudiantes chinos en otra academia de idiomas y, más adelante, en la Escuela Oficial de Idiomas. En tres años, su nivel de castellano era lo suficientemente bueno como para realizar tareas de interpretación. Después de tres años de ejercer de profesora en la academia de su compatriota, en 2006 funda una propia a medias con su novio español, un antiguo alumno de lengua china cuyo interés por este idioma era profesional. La decisión que motivó la creación de una academia de lenguas fue la creciente demanda de profesorado natural de China, unida a las necesidades lingüísticas de los migrantes y las migrantes de este país asiático — sus alumnos son tanto españoles como chinos. Yang Mei ahora le dedica menos horas a enseñar chino. Ha contratado a varias profesoras nativas más procedentes del noreste con las que cubrir las necesidades formativas. La demanda de enseñanza de castellano ha crecido menos, por eso ella se encarga de enseñar el nivel elemental a sus alumnos compatriotas. Hace un año se casó con su novio español y ya está embarazada de un niño. Según manifiesta, la familia de su marido la ha acogido muy bien. Las familias respectivas aún no se conocen y están planeando un viaje a su ciudad cuando el bebé pueda hacerlo en avión, para presentárselo a sus padres. Piensa disfrutar de su baja maternal completa y luego seguir trabajando, y tiene la ayuda de su suegra española para cuidar del bebé hasta que lo escolarice.

La apuesta de asentamiento de Yang Mei está centrada en lo local, entendiendo por tal una estrategia de inserción laboral que se caracteriza por la oferta de un servicio especializado a la población (capital humano), mediante el cual se obtiene un capital simbólico que la distingue del resto del colectivo étnico al cual pertenece por origen. La inserción laboral tiene en común con las per- 
sonas de Qingtian el estilo emprendedor, pero el tipo de actividad se encuadra en la categoría de profesional liberal. La cualificación previa a la migración se transforma en destino en valor añadido para la población, la economía y el mercado nacional. La incorporación de una oferta destinada al mercado chino es una operación empresarial más para ampliar cuota de mercado sin mucha inversión en la obtención de mayores beneficios. La apuesta de la vía local de inserción se consolida gracias al matrimonio que, directamente, proporciona a Yang Mei una familia en destino.

En el futuro próximo, Yang Mei deberá conciliar la vida familiar y la laboral, y compartirá con muchas madres nacionales la baja por maternidad, la ayuda de la familia extensa y la escolarización temprana de su futuro hijo, una combinación de opciones a partir de los recursos que ofrece la sociedad de destino a una madre que se identifica con su cultura familiar.

La relación con la familia originaria se mantiene utilizando los mismos recursos que sus compatriotas: llamadas telefónicas, vídeos de la boda y de la familia española, y envío de remesas para festejar el año nuevo chino, además de las contadas ocasiones en que sus padres y su hermano han necesitado dinero. Sin embargo, el significado, la intención de los mismos gestos son diferentes a los del resto de sus compatriotas de origen chino. Yang Mei considera que su prioridad familiar la constituyen su marido y su hijo, futuro ciudadano español al que le gustaría enseñar su lengua y su cultura. Opina que la socialización de su hijo será diferente a la de sus primos españoles por estar en contacto con dos culturas, pero tampoco se engaña con el alcance de la trasmisión cultural materna. En este sentido, las relaciones de su hijo con su propia familia natal serán menos intensas y fluidas que las que tendrá con su familia paterna. Es el precio de una estrategia de asentamiento local. Y es precisamente en este aspecto donde las relaciones familiares transnacionales de Yang Mei tienen un alcance distinto: la familia extensa qingtianesa no renuncia a la sinización (proceso de enculturación china) de sus hijos e hijas nacidos en España.

La estrategia de inserción laboral de las mujeres procedentes del noreste y de las grandes urbes que siguen un itinerario local en función de su cualificación y su competencia lingüística es posible, debido, entre otros motivos, a la demanda que existe en la sociedad de destino de personas que faciliten la comunicación con los migrantes extracomunitarios. Así, este perfil de mujeres cualificadas son las que más acceso tienen a la contratación laboral con las administraciones públicas, las entidades bancarias, los centros educativos, etc. Este trabajo de cuello blanco etnificado es demandado por empleadores nacionales, fuera del nicho étnico económico chino, aunque, paradójicamente, está relacionado con el colectivo chino, pues la mayor parte de los servicios que ofrece van destinados de algún modo a su presencia en el país o a las relaciones económicas y culturales con China. En la estrategia local de inserción laboral, la etnicidad, asociada a la diversidad y gestionada desde la sociedad de destino, constituye una habilidad profesional de las mujeres con más capital humano y menos capital social étnico. 


\section{Conclusión}

La presencia china en España está compuesta mayoritariamente por las personas originarias del sur de la provincia meridional y litoral de Zhejiang. Un colectivo que cuenta con una trayectoria larga de asentamiento estructurado desde el punto de vista económico y social en torno a las empresas familiares. Empresariado étnico y familias transnacionales son los elementos más definitorios en la combinación de estrategias que desarrollan con el objetivo de asegurar el éxito de su proyecto migratorio. Ambos elementos enmarcan las dimensiones laborales, familiares y sociales de los integrantes de este colectivo.

Las madres qingtianesas concentran sus esfuerzos más en el ámbito productivo de la empresa que en el reproductivo, sin por ello renunciar a establecer vínculos afectivos con sus hijos e hijas, incluso en los casos de transnacionalización de la familia nuclear cuando las niñas y los niños son cuidados en China. La ideología familista rural china asume la maternidad transnacional como una relación más de parentesco con las familias empresarias migrantes en Europa.

El transnacionalismo preponderante en la inserción de las personas del sur de China no es la estrategia más común para las que proceden de otras zonas con menos tejido y volumen social. A excepción de la vía matrimonial con miembros de la comunidad china meridional, más frecuente para los hombres que para las mujeres del noreste chino, el resto no dispone de una red familiar con la que establecer un proyecto migratorio común. Así, el localismo se erige en la opción disponible para quienes cuentan con las habilidades y/o la capacitación que la sociedad de destino demanda. El matrimonio con personas locales también refuerza esta vía de inserción y, en este caso, son las mujeres procedentes del noreste las que se casan con varones nacionales, hipergamia femenina para consolidar la movilidad social ascendente en destino, objetivo del proyecto migratorio.

Las mujeres chinas residentes en España buscan mejorar la condición socioeconómica de sus familias, como acredita su participación activa en el sistema productivo empresarial o laboral. La estrategia de inserción laboral viene determinada por la cultura familiar y social propia del origen geográfico, una estrategia (localismo versus transnacionalismo) que también condiciona la proximidad o la lejanía de su relación con la sociedad de destino.

En definitiva, existen alternativas al modelo dominante o tipo ideal hegemónico de las mujeres chinas en España configurado por aquellas que trabajan en empresas familiares cuyo origen se encuentra en el flujo migratorio procedente de Qingtian y, por extensión, en sus vecinos también rurales de Wenzhou, así como, en menor medida, en zonas rurales de Fujian. Estas alternativas proporcionan otros tipos ideales y corresponden a flujos más recientes procedentes de ámbitos urbanos del noreste de China y de la provincia de Shandong o de otros más antiguos pero minoritarios en el conjunto total de la población china en España, también de zonas urbanas como las grandes ciudades y metrópolis de Shanghai, Beijing y Guangzhou, así como de Hong Kong y Taiwan. 
Los tipos minoritarios añaden complejidad y profundidad en el análisis de la presencia china en España, pero se observa cómo afloran intereses comunes que superan la aparente diversidad en el tipo de inserción sociolaboral. En todos los casos, lo que se pone en juego son los recursos disponibles, sea capital social (redes colectivas, familiares y étnicas), capital humano (formación y nivel de educación, recursos humanos) o capital económico. A veces se potencia lo transnacional, y otras se favorece lo local, o se utilizan ambas estrategias en grado variable. La confrontación de la variabilidad en los modelos de asentamiento femenino chino en España nos ayuda a comprender mejor las lógicas de las prácticas sociales llevadas a cabo para conseguir los objetivos que originaron su migración.

\section{Referencias bibliográficas}

AÑón, María José y Miravet, Pablo (2005). «Paradojas del familismo en el Estado del bienestar: mujeres y renta básica». Cuadernos de Relaciones Laborales, 23 (2), 101-121.

BELTRÁN ANTOLín, Joaquín (1991). «Los chinos en Madrid: aproximación a partir de datos oficiales. Hipótesis para una investigación». En: Malestar cultural y conflicto en la sociedad madrileña. Madrid: Comunidad Autónoma de Madrid, 295-304.

- (2000). «La empresa familiar: Trabajo, redes sociales y familia en el colectivo chino». Ofrim/ Suplementos, 6, 129-153.

- (2003). Los ocho inmortales cruzan el mar: Chinos en Extremo Occidente. Barcelona: Edicions Bellaterra.

Beltrán Antolín, Joaquín y SÁrz López, Amelia (2001). Els xinesos a Catalunya: Familia, educació i integració. Barcelona: Alta Fulla / Fundació Jaume Bofill.

- (2005). «La inserción social y económica de las comunidades asiáticas en España». En: Anuario Asia Pacifico 2004. Barcelona: Casa Asia / Fundació CIDOB / Real Instituto Elcano, 361-370.

- (2006). «Comunidades asiáticas en Cataluña: Concentración y dispersión de su asentamiento y de sus actividades empresariales». En: Beltrán, J.; Betrisey, D.; LOPEZ, A.M. y SÁiz, A. Población y actividades económicas de las comunidades asiáticas en España. Documentos CIDOB-Asia, 11.

- (2008). «La comunidad pakistaní en España». Anuario Asia-Pacífico 2007. Barcelona: Real Instituto Elcano / Fundación CIDOB / Casa Asia, 207-216.

- (eds.) (2009). Empresariado asiático en España. Barcelona: Fundación CIDOB.

Beltrán, J.; Oso, L. y Ribas, N. (2006). Empresariado étnico en España. Madrid: Ministerio de Trabajo y Asuntos Sociales. Barcelona: Fundación CIDOB.

Betrisey NADAli, Débora (2009). «Empresariado asiático en Madrid». En: Beltrán, Joaquín y SÁIZ, Amelia (eds.). Empresariado asiático en España. Barcelona: Fundación CIDOB, 141-179.

BofULIN, Martina (2010). «Sending love through infant formula: (re)making of the Chinese transnational family in Europe». Comunicación presentada a la 11th EASA Biennial Conference, Maynooth, Irlanda, 24-27 de agosto.

Bourdieu, P. (1986). «The forms of capital». En: RiCHARDSON, J. (ed.). Handbook of Theory and Research for the Sociology of Education. Nueva York: Greenwood Press. 241-258. 
Camarero Rioja, Luis A. y García Borrego, Iñaki (2004). «Los paisajes familiares de la inmigración». RES: Revista Española de Sociología, 4, 173-198.

Ceccagno, Antonella (2007). "Compressing Personal Time: Ethnicity and Gender within a Chinese Niche in Italy». Journal of Ethnic and Migration Studies, 33 (4), 635-654.

Christiansen, Flemming (2003). Chinatown, Europe: An exploration on overseas Chinese identity in the 1990s. Londres: Routledge Curzon.

Douw, Leo; HuAng, Cen y Godley, Michael R. (eds.) (1999). Qiaoxiang Ties: Interdisciplinary Approaches to "Cultural Capitalism» in South China. Londres: Kegan Paul International.

GESES (Grupo de Estudios sobre Sentimientos, Emociones y Sociedad) (2008). Servidoras sin fronteras: Migración femenina filipina y redes de cuidado. Bellaterra: Universitat Autònoma de Barcelona.

Hoe, Yow Cheun (2004). «Detraditionalised and Renewed Qiaoxiang Areas: Case Studies of Panyu and Wenzhou in the Reform Period since 1978». Comunicación presentada en la 5th Conference of the International Society of the Study of Chinese Overseas. Elsinore, Dinamarca, 10-14 de mayo.

Kulp, Daniel H. (1925). Country Life in South China: The Sociology of Familism. Nueva York: Bureau of Publications, Teachers College, Columbia University.

LAU, Siu-Kai (1978). «From traditional familism to utilitarianistic familism: The metamorphosis of familial ethos among the Hong Kong Chinese». Occasional Paper, 78. Social Research Centre. Hong Kong: The Chinese University of Hong Kong.

LeVY, Florence (2005a). «Les migrations des femmes du Nord de la Chine: l'exil, alternative à une situation de déclin?». En: MANRY, Véronique y RiBAS MATEOS, Natalia (eds.). Actes du colloque "Mobilités au féminin», organizado por el Laboratoire Méditerranéen de Sociologie, Maison Méditerranéenne des Sciences de l'Homme, CNRS, Tanger.

- (2005b). "Les femmes du Nord de la Chine, une migration au profil atypique». Hommes et migrations, $1254,45-57$.

LeVY, Florence y LiEBER, Marylène (2008). «Northern Chinese women in Paris: The illegal immigration-prostitution nexus». Social Science Information, 47 (4), 629-642.

LI, Minghuan (1999). "“To get rich quickly in Europe!”: Reflections on migration motivation in Wenzhou». En: PIEKE, Frank y MALle, Hein (eds.). Internal and International Migration. Chinese Perspectives. Richmond: Curzon, 181-198.

Lin, Yueh-Hwa (1947). The Golden Wing: A Sociological Study of Chinese Familism. Nueva York: Oxford University Press.

Moraga Reyes, Jorge (2010). Chinos en Asturias: La reciprocidad en el imperio del cálculo. Gijón: Museu del Pueblu d'Asturies.

NiETO, Gladys (1998). «LLa enseñanza, por vocación...”. Identidad nacional y mujeres inmigrantes chinas». Ofrim Suplementos, 3, 143-161.

- (2001). Las asociaciones chino-españolas en la construcción de una comunidad imaginada. Tesis doctoral. Universidad Autónoma de Madrid.

- (2003). «La inmigración china en España: Definiciones y actuaciones sobre integración social». Revista CIDOB d'Afers Internacionals, 63, 167-189.

PAJARES, Miguel (2010). Inmigración y mercado de trabajo. Informe 2010. Madrid: Ministerio de Trabajo y Asuntos Sociales.

PARELLA, Sònia (2007). «Los vínculos afectivos y de cuidado en las familias transnacionales: Migrantes ecuatorianos y peruanos en España». Migraciones Internacionales, 4 (2), 151-188. 
Parreñas Salazar, R. (2001). Servants of Globalization: Women, Migration and Domestic Service. California: Standford University Press.

Parreñas, R. (2003). «The Care Crisis in the Philippines: Children and Transnational Families in the New Global Economy». En: EHrenreich, B. et al. Global Women: Nannies, Maids and Sex Workers in the New Economy, Nueva York: Henry Holt and Company.

- (2005). «Long distance intimacy: class, gender and intergenerational relations between mothers and children in Filipino transnational families». Global Networks, 5 (4), 317-336.

Pedone, Claudia (2007). «Familias transnacionales ecuatorianas: estrategias productivas reproductivas». En: Bretón, V.; García, F.; Jové, A. y Vilalta, M.J. Ciudadanía y exclusión: Ecuador y España frente al espejo. Madrid: Catarata, 251-278.

PIEKE, Frank (2006). "Comunidad e identidad en el nuevo orden migratorio chino». En: Beltran, Joaquín (ed.). Las diásporas de Asia Oriental en Europa Occidental. Documentos CIDOB-Asia, 13, 69-99.

PIEKE,, Frank, et al. (2004). Transnational Chinese: Fujianese Migrants in Europe. Stanford: Stanford University.

PIEKE, Frank y MALle, Hein (eds.) (1999). Internal and International Migration. Chinese Perspectives. Richmond: Curzon.

Pina-Guerassimoff, Carine (2006). "Gender and Migration Networks: New Approaches to Research on Chinese Migration to France and Europe». Journal of Chinese Overseas, 2 (1), 134-145.

Putnam, R. (2002). Solo en la bolera: Colapso y resurgimiento de la comunidad norteamericana. Barcelona: Galaxia Gutenberg / Círculo de Lectores.

Reis Oliveira, Catarina (2010). «La actividad empresarial china en Portugal». Monográfico "Comunidades asiáticas en la Europa mediterránea. Transnacionalismo y empresariado». Revista CIDOB d'Afers Internacionals, 92, 223-242.

Ribas-Mateo, Natalia y Oso, Laura (2005). "Filipinas in Spain: Learning to do domestic labour». En: SpaAn, E.; Hillmann, F. y Naerssen, T. van. Asian Migrants and European Labour Markets: Patterns and processes of immigrant labour market insertion in Europe. Londres: Routledge, 159-176.

SÁIz LÓPEZ, Amelia (2001). Utopía y género: Las mujeres chinas en el siglo XX. Barcelona: Edicions Bellaterra.

- (2006). Procesos de socialización de los hijos e hijas de las familias de origen chino. Barcelona: Fundació Jaume Bofill.

- (2007). "Mujeres en la empresa familiar: El caso de las empresarias asiáticas». Revista CIDOB d'Afers Internacionals, 78, 57-76.

- (2010). «Procesos, convergencias y variaciones en el empresariado femenino de origen asiático en España». Monográfico "Comunidades asiáticas en la Europa mediterránea: Transnacionalismo y empresariado». Revista CIDOB d'Afers Internacionals, 92, 57-76.

SOLÉ, Carlota y LuRBE, Kàtia (2006). Inmigración comunitaria: discriminación inversa? Barcelona: Anthropos.

TARriUS, Alain (2004). «Más allá de los Estados-nación: sociedades, culturas y redes de emigrantes en el mediterráneo occidental»: En: AUBARELL, Gemma y ZAPATA, Ricard (eds.). Inmigración y procesos de cambio: Europa y el Mediterráneo en el contexto global. Barcelona: Icaria, 305-315.

YeOH, B. HuAng, S. y LAM, T. (2005). «Transnationalizing the "Asian” family: Imaginaries, intimacies and strategic intents». Global Networks, 5 (4), 307-315. 